\title{
The Basic Principles of Kin Sociality and Eusociality: Human Evolution
}

\author{
Ding-Yu Chung \\ Utica, MI, USA \\ Email:dy_chung@yahoo.com
}

Received 17 December 2015; accepted 25 January 2016; published 28 January 2016

Copyright (C 2016 by author and Scientific Research Publishing Inc.

This work is licensed under the Creative Commons Attribution International License (CC BY). http://creativecommons.org/licenses/by/4.0/

c) (i) Open Access

\section{Abstract}

The paper posits that kin sociality and eusociality are derived from the handicap-care principles based on the need-based care to the handicappers from the caregivers for the self-interest of the caregivers. In this paper, handicap is defined as the difficulty to survive and reproduce independently. Kin sociality is derived from the childhood handicap-care principle where the children are the handicapped children who receive the care from the kin caregivers in the inclusive kin group to survive. The caregiver gives care for its self-interest to reproduce its gene. The individual's gene of kin sociality contains the handicapped childhood and the caregiving adulthood. Eusociality is derived from the adulthood handicap-care principle where responsible adults are the handicapped adults who give care and receive care at the same time in the interdependent eusocial group to survive and reproduce its gene. Queen bees reproduce, but must receive care from worker bees that work but must rely on queen bees to reproduce. A caregiver gives care for its self-interest to survive and reproduce its gene. The individual's gene of eusociality contains the handicapped childhood-adulthood and the caregiving adulthood. The chronological sequence of the sociality evolution is individual sociality without handicap, kin sociality with handicapped childhood, and eusociality with handicapped adulthood. Eusociality in humans is derived from bipedalism and the mixed habitat. The chronological sequence of the eusocial human evolution is 1) the eusocial early hominins with bipedalism and the mixed habitat, 2) the eusocial early Homo species with bipedalism, the larger brain, and the open habitat, 3) the eusocial late Homo species with bipedalism, the largest brain, and the unstable habitat, and 4) extended eusocial Homo sapiens with bipedalism, the shrinking brain, omnipresent imagination, and the harsh habitat. The omnipresence of imagination in human culture converts eusociality into extended eusociality with both perception and omnipresent imagination.

\section{Keywords}

Kin Sociality, Eusociality, Evolution, Kin Selection, Group Selection, The Handicap-Care Principle, Human Evolution, Supernatural, Hamilton's Rule, Domestication, Shrinking Brain, Upper 


\section{Paleolithic Revolution}

\section{Introduction}

Eusociality [1] is the highest level of organization of animal sociality in certain insects, crustaceans, and mammals. Ants, bees, and termites are eusocial animals. The three criteria for eusociality are division of labor, overlapping generations, and cooperative care of young including ones that are not their own. Under the three criteria, human is a species of eusocial ape [2]. Being highly cooperative within a group, eusocial species are more plentiful, inhabit more of the habitat, and utilize more of the accessible resources than non-eusocial species.

The two different explanations of eusociality are kin selection and group selection. For kin selection, eusociality is explained by inclusive fitness [3] [4] that allows eusocial kin group formation among genetically related individuals. Kin selection can explain eusociality in the bees with high genetic relatedness. However, genetic relatedness cannot explain all eusocial and non-eusocial organisms. For example, some social groups with high genetic relatedness are not eusocial, so it is necessary to explain eusociality by group fitness for group selection based on the behaviors good for group [2] [5] [6]. A major problem for group selection is that group selection based on good for group in group fitness is not an evolutionary stable strategy, while kin selection based on individual's genetic relatedness and self-interest is an evolutionary stable strategy.

This paper posits that kin sociality and eusociality are derived from the handicap-care principles based on the instinctive need-based care to the handicappers from the caregivers for the self-interest of the caregivers. In this paper, handicap is defined as the difficulty to survive and reproduce independently. For kin selection, the handicap is the childhood handicap where all children are handicappers unable to survive independently. The childhood handicap solicits the care from kin adult caregivers. The usual first caregiver is maternal caregiver from mother alone. The increased childhood handicap requires additional caregivers first from paternal caregiver, and then sibling, uncle-aunts, and grandparent caregivers. The fitness is inclusive fitness as the combined fitness of handicapper and caregivers based on genetic relatedness. A caregiver gives care for its self-interest to reproduce its gene. The individual's gene of kin sociality contains the handicapped childhood and the caregiving adulthood.

For eusociality, the handicap is the adulthood handicap where responsible adults are handicappers unable to survive and reproduce independently. The responsible handicapped adults themselves are responsible to care, but they at the same time require the care to survive and reproduce. The responsible handicapped adults are handicapper and caregiver at the same time. The result is the interdependent eusocial group where adults rely on one another interdependently to survive and reproduce. For example, in eusocial bees, queen bees reproduce but must receive care from worker bees to survive, while worker bees procure food but must rely on queen bees to reproduce their genes. A caregiver gives care for its self-interest to survive and reproduce its gene. The individual's gene of eusociality contains the handicapped childhood, the handicapped adulthood, and the caregiving adulthood. Based on individual's gene and self-interest, interdependent fitness is an evolutionary stable strategy.

The chronological sequence of the sociality evolution is individual sociality without handicap, kin sociality the handicapped childhood, and eusociality with the handicapped adulthood. For the human eusocial evolution, eusociality is explained by bipedalism and the mixed habitat. The human brain expansion is explained by the increasingly challenging habitats. The shrinking human brain over the past 30,000 years is explained by the domestication, resulting in extended eusociality with omnipresent imagination. Section 2 describes the handicap-care principle. Section 3 explains the sociality evolution. Section 4 describes the human eusocial evolution.

\section{The Handicap-Care Principle}

The paper posits that kin sociality and eusociality are derived from the handicap-care principles based on the instinctive need-based care to the handicappers from the caregivers for the self-interest of the caregivers. In this paper, handicap is defined as the difficulty to survive and reproduce independently, and caregiving is defined as the care giving to a handicapper by a caregiver in order to help the handicapper to survive and reproduce. The handicap-care principle can be derived from the Hamilton's Rule. In the conventional Hamilton's Rule [3] [4],

$$
c<r b \text {, }
$$


where $c$ is the reproductive cost in number of offspring equivalents to the altruist, $r$ is the relatedness coefficient between beneficiary and altruist, and $b$ is the reproductive benefit in number of offspring equivalents to the beneficiary of the altruistic behavior. Every parent transmits $50 \%$ of its genetic information to each offspring for the relatedness coefficient $r=0.5$. Siblings share half of each parent's contribution to their genome for $r=0.5$. Grandparents share $r=0.25$. Nephews share $r=0.25$, and cousins share an $r=0.125$. The reproductive cost (c) and the reproductive benefit $(b)$ can be described by $r$. For example, an altruist is willing to save five cousins ( $r=$ 0.125 ) with the total reproductive benefit $=5 \times 0.125=0.625$ at the expense of one offspring with the reproductive cost $=0.5$.

The conventional Hamilton's Rule as a convention game theory typically assumes all individuals in game theory are independent adults without the differentiation between adult and child and the differentiation between handicapper and independent individual. The handicap-care principle has the differentiation between adult and child and the differentiation between handicapper and independent individual. For the Hamilton's Rule in terms of the handicap-care principle, altruist is caregiver, beneficiary is handicapper, cost is the investment of caregiver to help handicapper to survive and reproduce, and the benefit is the care received by handicapper to survive and reproduce. The handicap-care principle is essentially the needed-based transfer system [7] [8] derived from the Hamilton's Rule. In the needed-based transfer system, resource sharing is based on the need of the recipient (i.e., need-based transfers) rather than on strict account-keeping.

The paper posits that the basic principle of kin sociality is the childhood handicap-care principle where the children are the handicapped children who receive the care from the kin caregivers in the inclusive kin group to survive for the self-interest of the kin caregivers. Children are handicappers, because they have difficulty to survive independently without the help of kin caregivers. In the Hamilton's Rule in terms of the handicap-care principle, the handicapper is the handicapped child unable to survive independently, the caregiver is the kin caregiver, and the care is the care required for handicapped child to survive. The group size of the kin caregiver group increases with the increased care required for handicapped children to survive. The usual first caregiver is maternal caregiver alone. The increased childhood handicap requires additional caregivers first from paternal caregiver, then sibling caregivers, and then adult sibling (uncles and aunts) caregivers and grandparent caregivers, resulting in the kin caregiver group. The fitness of kin sociality is inclusive fitness as the combined fitness of handicapper and kin caregivers based on genetic relatedness. Inclusive fitness is expressed in the kin social individual's gene containing the handicapped childhood and the caregiving adulthood. The caregiver in kin group derived from the childhood handicap-care principle must instinctively give care to its children, because without giving care to its children, the caregiver loses the reproduction of its gene. Therefore, a caregiver in a kin social group gives care for its self-interest to reproduce its gene.

The Hamilton's Rule can be expressed as the kin sociality investment formula as Equation (2). In the kin sociality investment formula, the return of the investment (cost) from the caregivers is the survival of genetically related children from birth to adulthood. The kin sociality investment $\left(I_{k}\right)$ per caregiver is as follows.

$$
I_{k}<\frac{m \sum_{j=1}^{n} r_{j}}{n f},
$$

where $m$ is number of the children, $n$ is the number of the caregivers, $j$ is individual caregiver from 1 to $n, f$ is the environmental return enhancement factor, and $r$ is the relatedness coefficient as the degree of genetic relatedness between the child and the caregiver. The environmental return enhancement factor is to enhance the return by environmental factors, such as the birth time and the birth location of children. The caregivers include mother $(r=0.5)$, father (0.5), sibling (0.5), uncle-aunt (0.25), and grandparents (0.25). Equation (2) indicates that an individual caregiver with a higher relatedness coefficient invests individually more. The kin sociality investment $\left(I_{k}\right)$ per caregiver and the child-to-caregiver ratio $(\mathrm{m} / \mathrm{n})$ correspond to the cost $(c)$ and benefit $(b)$, respectively, in the Hamilton's Rule. When a new male lion dominates a kin group, the male lion terminates the lives of the child lions in the kin group in order to terminate the investment in the child lions from the previous kin group, and to start a new investment in a new kin group from the male lion by mating with the female lion.

The paper posits that the basic principle of eusociality is the adulthood handicap-care principle where responsible adults are the handicapped adults who give care and receive care at the same time in the interdependent eusocial group to survive and reproduce. The responsible handicapped adults themselves are responsible to care, 
but they at the same time require the care to survive and reproduce. The responsible handicapped adults are handicapper and caregiver at the same time. For example, in eusocial bees, queen bees reproduce but must receive care from worker bees to survive, while worker bees procure food but must rely on queen bees to reproduce their genes. The fitness of eusociality is interdependent fitness expressed in the eusocial individual's gene containing the handicapped childhood, the handicapped adulthood, and the caregiving adulthood. The caregiver in eusocial group derived from the adulthood handicap-care principle must instinctively give care to not only its children but also to other handicapped adults, because without giving care to other handicapped adults who provide the care for the caregiver, the caregiver cannot survive or reproduce. Therefore, a caregiver in a eusocial group gives care for its self-interest to survive and reproduce its gene. Based on individual's gene and self-interest, interdependent fitness is an evolutionary stable strategy.

The interdependent handicapped caregivers become the interdependent specialists focusing in one task without doing other tasks for the division of labor. Essentially eusociality becomes superorganism where the interdependent specialists are like the interdependent specialized cells in multicellular organism. The interdependent specialists enhance the return on investment through highly cooperative interdependence and the high expertise of specialization by specialist. The enhancement of the return on investment is manifested in that even though eusociality is rare, eusocial species are more plentiful, inhabit more of the habitat, and utilize more of the accessible resources than non-eusocial species. As in multicellular organism with interdependent specialized cells, the enhancement of the return on investment increases with increased number of interdependent specialists. The eusociality sociality investment formula is the kin sociality modified by the number of the interdependent specialists. The eusociality investment $\left(I_{e}\right)$ per caregiver is as Equation (3).

$$
I_{e}<\frac{m \sum_{j=1}^{n} r_{j}}{n f s},
$$

where $s$ is the number of the interdependent specialist roles to enhance the return on investment in a eusocial group. The eusocial interdependent specialist in the division of labor is a caregiver and a handicapper at the same time, so the interdependent specialist focuses in one specialized task without doing other tasks for the division of labor. For examples, for eusocial bees, $s$ is equal to 3, consisting of fertile queen bee, fertile drone bee, and infertile worker bee. Fertile queen bee and drone bee focus in reproduction task without doing survival task in terms of food procurement. Infertile worker bee focuses in survival task in terms of food procurement without doing reproduction task. For the eusocial early Homo species, the number of the interdependent specialists is 3 , consisting of fertile homemaker-gatherer, infertile homemaker-gatherer, and fertile explorer-hunter.

\section{The Sociality Evolution}

The chronological sequence of the sociality evolution is individual sociality based on individual fitness without handicap, kin sociality based on inclusive fitness with handicapped childhood, and eusociality based on interdependent fitness with handicapped adulthood.

$$
\begin{aligned}
& \stackrel{\substack{\text { individul sociality based on individual fitness } \\
\text { handicapped childhood }}}{\stackrel{\text { handicapped adulthood }}{\longrightarrow} \text { kin sociality based on kin fitness }} \text { eusociality base on interdependent fitness }
\end{aligned}
$$

for individual sociality. $I=0$ and $n=0$ without the investment and without caregiver, respectively in Equation (2). For kin sociality, $n>0$ for non-zero number of caregivers and $s=1$ without the division of labor in Equation (3). For eusociality, $n>0$ for non-zero number of caregivers and $s>1$ for more than one specialist in the division of laborin Equation (3).

Individual sociality based on individual fitness without handicap is basically to overcome the handicap of children by the quantity, and birth location, birth time of children without any kin care. It is an evolutionary stable strategy. The cooperation in individual sociality is based on reciprocity (reciprocal altruism) on strict account-keeping. The complexity of evolved organisms leads to a long and vulnerable childhood, resulting in the handicapped childhood requiring kin care first by maternal care. In the abundant and secure environment, maternal care alone such as in orangutan and bear is sufficient. The animals with only maternal care are called soli- 
tary animals. The increased childhood handicap requires additional caregivers first from paternal caregiver, then sibling caregivers, and then adult sibling (uncles and aunts) caregivers and grandparent caregivers. The caregiver kin group can be a very large group which has genetically closely related kin group within many other genetically remotely related kin groups such as in a large flock of birds and a large herd of animals. Kin selection based on inclusive fitness dominates natural selection, because the highly cooperative caregiver kin group based on individual's gene is a highly robust evolutionary stable strategy. Eusocial selection with the handicapped adulthood is rare, because normally the species with the handicapped adulthood become extinct. It is rare that the handicapped adulthood leads to the interdependent eusocial group based on the division of labor where adults are both handicappers and caregivers, and rely on one another for survive and reproduce.

The social roles of eusocial insects are based on gene regulation that increases with increased eusocial complexity starting from solitary insects [9]. Gene regulation is the change of genetic expression by interacting with surrounding environment such as food intake, pheromone control, and sound control. Gene regulation allows the change of one eusocial insect to different forms in the same way as the change of a cell in multicellular organism to different forms by interacting with the surrounding cells. The chronological sequence of the evolution of eusocial insect is proposed to be solitary insect, social insect, and eusocial insect by gene regulation.

$$
\text { solitary insect } \longrightarrow \text { social insect } \stackrel{\text { gene regulation }}{\longrightarrow} \text { eusocial insect }
$$

For solitary insect, $n=1$ with only one caregiver in Equation (2). For social insect, $n>1$ for more than one caregiver and $s=1$ without division of labor in Equation (3). For eusocial insect, $n>1$ for more than one caregiver, and $s>1$ for more than one specialist in the division of labor in Equation (3).

For bees, queens are produced as a result of receiving larger quantities of special food (royal jelly) during development (larva). The pheromones produced by a queen give individual identity to a colony and control the behaviors of other bees. The gene regulation increases with increased eusocial complexity. In terms of multicellular organism, fertile eusocial insect is like germ cell, while infertile eusocial worker insect is like somatic cell.

\section{The Human Eusocial Evolution}

The human eusocial evolution is proposed to be started as solitary orangutan-like ape when the environment was the abundant and secure environment with extensive rainforest like the rainforest environment of current solitary orangutan. The graduate drying and cooling of African 13 million years ago converted solitary orangutan-like ape into social ape with less abundant and secure environment in the less extensive rainforest. The social apes evolved into hominins, chimpanzees, bonobos, and guerrillas in Africa with further diminishing rainforest.

Around 6 millions of years ago, a major climate change reduced some part of forested area in Africa to woodland where Ardi (Ardipithecus ramidus) [10] was evolved. Ardi, the oldest human ancestor (4.4 million year old) discovered, lived on woodland. Similar to other apes, Ardi's skull encased a small brain -300 to 350 cc. She lived in the mixed habitat of grassy woodland with patches of denser forest, and freshwater springs. The appearance of woodland caused the evolution from the social orangutan-like common ancestor to produce the bipedal human ancestors, the early hominins. Woodland allowed increasingly amount of food from bushes and low branches, which could be seen and reached from the ground. According to the observation [11] in Africa, chimpanzees today move on two legs most often when feeding on the ground from bushes and low branches. When food resources are scarce or unpredictable, chimpanzees use upright locomotion to improve food carrying efficiency. It suggests that the same might have occurred among the early hominins. Comparing to forest area, woodland area had scarcer food resources.

For reaching food from low branches on woodland and to carry food, the early hominins came down to the ground partly (not entirely) from living among trees, and adopted bipedalism as the way to move on the ground. However, Ardi's foot was primitive with an opposable big toe that could not provide a push needed for efficient bipedal walking. Ardi had a more primitive walking ability than later hominins, and Ardi had a somewhat awkward gait when on the ground. Its feet were still adapted for grasping trees rather than walking for long distances and running fast on the ground. (For apes, the quadrupedal knuckle-walking like gorillas, bonobos, and chimpanzees was faster and better way than Ardi's primitive awkward bipedalism to move on the ground.) The movement handicap of bipedalism on the ground was serious for very young, very old, and pregnant early hominins. To the early hominins in the mixed habitats, the area with many tall trees was the safe home area where very young, very old, and pregnant hominins stayed, and where they could escape quickly to the safety in tall 
trees, and the area with few tall trees was the unsafe exploration area for the exploration to find extra foods that could not be found in the safe home area. The two free hands from bipedalism allowed the early hominins to carry a large quantity of food home from the exploration as proposed by C. Owen Lovejoy [12] and to carry simple defensive weapons such as sticks and stones to defense against large predators in the unsafe area. The exploration also allowed them to scavenge meats left by carnivores. Consequently, the bipedalism and the mixed habitat divided the early hominins into the home hominins who stayed in the safe home area and the exploration hominins who explored in the unsafe exploration area during daytime and return home at night.

The caregiver interdependent specialists for the early hominins were the homemaker-forager who took care of children and foraged in the safe home area and the explorer-forager who explored and foraged in the unsafe exploration area. A good homemaker-forager was able to do multitask and navigate through landmarks (different trees) as women today. A good explorer-forager was able to have a good sense of direction (orientation in space) for exploration and strong upper body strength to carry foods and defensive weapons as men today. The homemaker-forager evolved into fertile homemaker-forager and infertile homemaker-forager. Women today become infertile after menopause at about the age of 51. A today woman's best reproductive years are in her $20 \mathrm{~s}$. Fertility gradually declines in the $30 \mathrm{~s}$, particularly after age 35 . The three interdependent specialists of the early eusocial human ancestors were fertile homemaker-forager, infertile homemaker-forager, and fertile explorerforager. The eusocial interdependent specialists were derived from the mixed habitat and the bipedalism which initially produced two hand-like primitive soft feet and two free hands, resulting in the movement handicap (awkward walking) and the capability in carrying large quantities of foods home by free hands from the long distance forgers. The division of labor allowed the early hominins to take full advantage of the mixed habitat in terms of security and food procurement. The division of labor started the human eusocial evolution. The chronological sequence of the human eusociality is as follows.

$$
\text { solitary ape } \longrightarrow \text { social ape } \stackrel{\text { bipedalism/mixed habitat }}{\longrightarrow} \text { eusocial early hominins }
$$

For the eusocial early hominins, $s=3$ for the three specialists in the division of labor in Equation (3).

The human eusociality was enhanced by the communication through the free hands as sign language. Learning simple sign language does not require a large brain. Chimpanzee Washoe learned approximately 350 words of American Sign Language [13]. She was able to communicate with humans in sign language sentences, and there was no significant difference in quality between her use of gestural language and the use of ordinary speech by children. The free hands allowed the early hominins to communicate in sign language extensively in most occasions, especially during forages when the continuous communication among the members in a forage group was important. Gestural communication served as a steppingstone for the evolution of human symbolic communication. Gesture production in humans is so automatic that it is relatively immune to audience effects: blind subjects gesture at equal rates as sighted subjects to a known blind audience. Gestural communication as gestural language is the predecessor of spoken language [14]. The generally right-handed dominant hominin caused the development of the gestural language area (Broca's area) in the left-brain that eventually developed into the part for the spoken language later. Broca's area can be seen in endocasts from the early hominins Australopithecus. In the study by Hickok, Bellugi and Klima [15], the impairment for sign language patients was identical with that of speaking patients. At the hemispheric level the neural organization of sign language is indistinguishable from that of spoken language. The gestural communication by the free hands enhanced harmony in eusociality. The two important traits that distinguish early hominins from other apes are bipedalism and small canine teeth. Being eusocial, early hominins lost the large sharp canine teeth for continuous internal aggression and fighting that took place in some other apes.

Other apes evolved with different ways other than bipedalism to survive. For orangutan in dense rainforest, the feet are much more useful to climb trees than to walk on the ground, so orangutan did not develop bipedalism for walking. Gorillas, chimpanzees and bonobos did not develop bipedalism, because they needed fast and steady quadrupedal knuckle walking with the knuckle hands to escape from predators and for the large foraging ranges on the ground. The bipedalism of the early hominins evolved before the quadrupedal knuckle walking [16].

The early hominins developed later much better feet to overcome the initial movement handicap on the ground, but the early hominins continued to retain the tall tree area as their safe home area. They had long upper limbs, short femurs, curved finger bones, and other chimpanzee-like traits that indicate a mixture of arboreal and terrestrial adaptations. Arid climate that intensified in around 2.8 million years ago transformed the mixed habi- 
tat of grassy woodland with patches of denser forest, and freshwater springs into the open habitat of mixed grasslands and shrub lands with trees lining rivers and wetlands [17]. At the same time, habitat unpredictability was superimposed on the underlying aridity trend [18]. The open habitat with very few tall trees transformed the early hominins into the early Homo species. The first Homo species, Homo habilis, still retained some body features for climbing trees. Homo erectus after Homo habilis was completely terrestrial like humans.

Without the safety of tall trees for young children, old hominins, and pregnant hominins, the early hominins were not adaptable to the open habitat. Bipedalism and eusociality (the division of labor and communication) were good enough for the early hominins to survive in the mixed habitat with the protection of tall trees for about 4 million years. The survival in the open habitat requires three more factors for evolutionary adaptation, consisting of stone tools, controlled fire, and large brain. Without all five factors for evolutionary adaptation to the open habitat, the hominins became extinct in a short period of time.

The earliest evidence of the use of stone tools dates to 3.3 million years ago in Kenya [19]. The stone tools were made by the early hominins before the oldest known Homo fossil that is 2.8 million years old. It suggests that the early hominins without a large brain had the cognitive and manipulative abilities to carry simple stone toolmaking tasks. For the early hominins, scavenged meat from carcasses could be sliced using sharp edges of flakes, and scavenged bones were broken open with stones to access the marrow inside, The making and the application of simple stone tools by the early hominins did not cause a significant brain expansion. However, there were much more applications of stone tools in the open habitat than in the mixed habitat. As a result, the increase in the applications with new and diverse stone tools in the open habitat was a major reason for the expansion of the brain in the early Homo species. The application of stone tools in hunting tools quickly turned the early Homo species into the hunters of large animals in the open habitat. Hunting large animals required the division of labor and communication which already existed in eusociality of the early hominins. For the brain expansion of Homo habilis from $500 \mathrm{~cm}^{3}$ to $600 \mathrm{~cm}^{3}$ to improve communication further, Wernicke's area as the new language area was formed in addition to Broca's area for the original language area. Stone tools could be used to grind plants and to sharpen sticks to dig for tubers. The applications of stone tools were also in building protected home base with various barricades in the open habitat, preferably by rivers and lakes, and in caves. River and lakes provided water and protection. With the application of stone tools and the brain expansion, the three interdependent specialists became fertile homemaker-gatherer, infertile homemaker-gatherer, and fertile explorer-hunter in the open habitat. To hunt large animals also required the increase in body size. Homo erectus had a similar range of body sizes to modern humans.

Another important factor for survival in the open habitat was fire control. Based on reduced feeding time and molar size, cooking with fire was originated after the evolution of Homo but before or concurrent with the evolution of Homo erectus, which was around 1.9 million year ago [20]. It suggests that fire control occurred as early as 1.9 million years ago by the early Homo species. Fire control allowed the early Homo species to stay warm, cook food, ward off predators, and venture into harsh climates. Cooking with fire forced the early Homo species to live, cook, and eat together, encouraging close large social gathering and interaction. The brain of Homo erectus was doubled to $1100 \mathrm{~cm}^{3}$ by the increase in body size, the environmental adaptation to the open habitat of all different climates, and the social adaptation to the close large social gathering.

The period between 800,000 and 200,000 years ago is the period of strongest climate fluctuation worldwide. The open habitat became the unstable habitat in East Africa. The unstable habitat caused the fastest evolutionary enlargement of the brain relative to body size, resulting in the emergence of the late Homo species, including Homo sapiens and Neanderthals. Larger brains allowed the late Homo species to process and store information, to plan ahead, and to solve problems. A large brain provided versatile solutions to new and diverse survival challenges in the unstable habitat in East Africa. The chronological sequence of the evolution from the eusocial early hominins to the eusocial late Homo species is as follows.

$$
\begin{aligned}
& \text { 1. eusocial early hominins } \underset{\text { bipedalism/largest brain/unstable habitat }}{\stackrel{\text { bipedalism/larger brain/open habitat }}{\longrightarrow}} \text { 3. eusocial late Homo species } \\
& \stackrel{2}{\longrightarrow} \text {. eusocial early Homo species }
\end{aligned}
$$

For the eusocial early hominins, the eusocial early Homo species, and the eusocial late Homo species, $s=3$ for the three specialists in the division of labor in Equation (3).

The brain size of Homo species starts from about $600 \mathrm{~cm}^{3}$ in Homo habilis up to about $1600 \mathrm{~cm}^{3}$ in Neanderthals and Cro-Magnon people. Since then, the average human brain size has been shrinking over the past 30,000 
years about $10 \%$ in size from around $1550 \mathrm{~cm}^{3}$ to around $1440 \mathrm{~cm}^{3}$ in males, and from around $1500 \mathrm{~cm}^{3}$ to around $1240 \mathrm{~cm}^{3}$ in females [21]. This has happened everywhere in the world. One model to explain the brain shrinkage is the domesticated brain [22] [23]. Some 30 domesticated animals have lost brain volume, typically a 10 to 15 percent reduction compared with their wild progenitors. The brain shrinkage can be done by regulatory genes that determine the timing of the brain development, so the brain development is stopped before the fully independent adult stage to retain some characteristics of docile and dependent juvenile characteristics as the requirement for the domestication of animals with the reduction of strong-will and independent characteristics. Wolves are more persistent than dogs evolved from wolves in solving simple problems like how to open a box. Dogs are more readily give up in order to using humans as tools to solve problems for them in the same way that juvenile wolves are more readily to give up in order using their parents as tools to solve problems for them.

The paper posits that the supernatural as religion has domesticated humans since the harsh Upper Paleolithic Period from about 40,000 years ago. Humans have turned to the supernatural for strength and good fortune during the difficult time in the same way as dogs turning to humans for help. In this way, the supernatural has domesticated humans as humans have domesticated dogs. The Upper Paleolithic Period was a very difficult period that prompted humans turning to the supernatural for help. During the Upper Paleolithic Period, a number of sudden temperature drops reduced significantly the area for forest in Europe and Asia. The reduction of forest reduced the food supply, usable timber, and other non-food materials. During the harsh Upper Paleolithic Period, the human society was preoccupied with fertility and vitality for women and men, respectively. The imaginative female figurines and cave paintings appeared during the period. In most cases, the imaginative exaggerated and distorted female figurines were miniature sculptures of well-rounded female nudes with an overemphasis of the fleshy parts of the body (buttocks, stomach and chest). The sexual accent on the female breasts and the posterior are assumed by many to connote signs of fertility. The head and arms are mostly absent with the stress on the middle of the torso. Thighs tend to be exaggerated tapering into smaller legs. The head has no face. According to Alan F. Dixson and Barnaby J. Dixson, these female figurines symbolized and brought the hope for a well-nourished and fertile community facing grim winters and a scarce food supply [24]. In the imaginative cave paints, the animals were mystic large strong animals or mystic animals with horns that symbolized maturation and strength. According to David Lewis-Williams [25], the imaginative cave paintings involved hallucinatory or trance states by drugs or repetitive rhyme. The mystic animal pictures were conceived during the trance states. The mystic powerful animal cave paintings were presented as evidence of spirit journeys previously undertaken. These cave paintings symbolized and brought the hope for a vital and powerful community facing grim winters and a scarce food supply.

The female figurines and the cave painting symbolized the supernatural in terms of fertility for women and vitality for men, respectively. (These religious symbols evolved into fertility goddesses and warrior gods in the civilized society later.) The concept of the supernatural at the time of the Upper Paleolithic Period was considerably different from the current concept of the supernatural. At the time of the Upper Paleolithic Period, the supernatural was immanent supernatural that appeared everywhere as a part of all objects in the world. (The transcendental supernatural was developed later.) Anything unexplained or unusual was attributed to the supernatural. Everyone and everything was able equally to become an avatar, the incarnation of the supernatural. The symbols for the immanent supernatural were typically the exaggerated and distorted representation of the real natural objects to represent the unexplained and unusual characteristics of the immanent supernatural, so the symbols represented partly the natural and partly the supernatural. (Symbol is the result of the exaggeration of a specific feature of a real object.) Such symbols brought the immanent supernatural to help people.

During the Upper Paleolithic Period, there was the increasingly sharing of religious symbols for the immanent supernatural among different social groups. The enormous distribution of these female figurines implied a ritualistic exchange system with the figurines playing a central role in inter-group relations [26]. Practicing alternate states of the mind also became community rituals among different social groups, often led by shaman inside or outside of caves. The practicing of the alternate state of mind together promoted unity among different social groups. The sharing of the religious symbols brought about the sharing of survival information and resource among different social groups. The sharing actually improved the fertility and vitality of the groups involved, resulting in the validation of the power of the religious symbols. The result was the rise of the female figurine and cave painting religion. People spent much more energy and time to develop and make such religious symbols for the immanent supernatural, resulting in the Upper Paleolithic Revolution [27] with the rapid development and spread in religious art and the involved skills. 
Similar to the Industrial and Neolithic Revolutions, the Upper Paleolithic Revolution during the Upper Paleolithic period represents a short time span when numerous inventions appeared and cultural changes occurred. The revolution comprised new religions, technologies, hunting techniques, human burials, and artistic work. The human society became more cooperative especially in intergroup cooperation beneficial to the survival of humans during this harsh period. The supernatural as religion became a well-established tradition, spreading to all human societies in the world. The supernatural as religion has been ubiquitous in all human societies. The belief in the supernatural that is the belief in turning to the supernatural for help is the belief system of the dependence on the supernatural. The conformity to the belief system of the dependence favors the docile and dependent adults over strong-will (stiff-necked) and independent adults in the same way that the domestication of animals favors docile and dependent animals over strong-will and independent animals. The marginalization of strongwill and independent adults reduces the reproduction of strong-will and independent people, and enhances the reproduction of docile and dependent adults who have the shrinking brains in the same way that the domestication of animals reduces the reproduction of strong-will and independent animals, and enhances the reproduction of docile and dependent animals that have the shrinking brains. The beneficial Upper Paleolithic Revolution was a result of the supernatural as religion, while the shrinking brain is the side-effect of the domestication by the supernatural. Neanderthals already died out about 40,000 years ago [28], and the interbreeding between Neanderthals and Homo sapiens occurred about 50,000 to 60,000 years ago, so Neanderthals did not have the chance to develop the Upper Paleolithic Revolution.

The concept of the supernatural as religion is derived from the abstraction of imaginary objects by Maurice Bloch [29], who proposed that such development of imagination occurred at about the time of the Upper Paleolithic Revolution. The late Homo species are good in finding repetitive patterns (similarity-difference and causeeffect) in perceived objects as the abstraction of perceived objects [30]. The abstraction of perception allows animals to solve similar problems with the same patterns. It is a powerful problem solving tool. Unlike perceived objects, the abstraction of perception is immaterial, and does not correspond to any particular perceived objects, so the abstraction of perception is the steppingstone for imaginary objects which also do not correspond to any perceived objects. The abstraction of imaginary objects is the abstraction of imagination. The abstraction of imagination is equivalent to "theory of mind" to recognize (imagine) that the others exist to think (abstract) for themselves. In other words, you imagine thinking like another person. Autistic individuals with problems in imaginative capacities are incapable of theory of mind [31] [32]. The practical purposes of imagination are to imagine you thinking like another person to detect cheatings by the person and to imagine yourself in a hypothetical situation to detect dangers in the situation. The original purposes of human imagination were practical. The sequence of the evolution of the perception is perceived objects, the abstraction of perception based on the abstraction of perceived objects, imaginary objects, and the abstraction of imagination based on the abstraction of imaginary objects.

$$
\begin{aligned}
& \text { perceived objects } \longrightarrow \text { abstraction of perception } \\
& \longrightarrow \text { imaginary objects } \longrightarrow \text { abstraction of imagination }
\end{aligned}
$$

The expansion of imaginary objects for the late Homo species involved the imaginary objects such as artificial artistic objects [33] before the Upper Paleolithic Revolution. The gigantic expansion of the abstraction of imagination involved the supernatural when humans turned to the supernatural for help desperately during the harsh Upper Paleolithic Period. For the supernatural as religion, the imaginary objects are the imaginary supernatural agents behind all perceived objects, and the abstraction of imagination is the supernatural as the repetitive pattern of all supernatural imaginary agents behind all perceived objects. In terms of the abstraction of imagination as theory of mind, humans recognize (imagine) that the supernatural exists to think (abstract) oneself. The shrinking human brain over the past 30,000 years is explained by the domestication of humans by the supernatural which is basically indistinguishable from the self-domestication by the abstraction of supernatural imagination. Both domestications basically do not depend directly on the abstraction of perception.

The abstraction of imagination has been expanded rapidly to all different areas since the Upper Paleolithic Revolution. According to Maurice Bloch, imagination becomes omnipresence in human culture [29]. Civilized religions combine the abstractions of supernatural, tribal, moral, altruistic, historical, and social imaginations. In civilized religions, the imaginations are superimposed on the perceptions to produce the emotions for the imaginations. The abstraction of mathematical imagination is the base for natural science and engineering. The ab- 
straction of logical imagination is the base for social science and philosophy. The abstraction of artistic imagination is the base for abstract art. None of the abstractions of imagination corresponds exactly to the abstraction of perception. The purposes of perception and the abstraction of perception are entirely for survival and reproduction here and now, not for eternal reality. The abstractions of imagination which deviates from the abstraction of perception may actually closely correspond to eternal reality as shown in natural science as the eternal reality of the physical nature which cannot be modeled by the abstraction of perception for survival and reproduction here and now.

The omnipresence of imagination in human culture converts eusociality into extended eusociality with both perception and omnipresent imagination. As a result, in the harsh habitat during the Upper Paleolithic Period, the eusocial late Homo species evolved into the extended eusocial Homo sapiens with the shrinking brain and omnipresent imagination. The four interdependent specialists for the late prehistoric Homo sapiens were fertile homemaker-gatherer, infertile homemaker-gatherer, fertile explorer-hunter, and religious specialist as the abstraction of supernatural imagination specialist. The chronological sequence of the eusocial human evolution is 1) the eusocial early hominins with bipedalism and the mixed habitat; 2) the eusocial early Homo species with bipedalism, the larger brain, and the open habitat; 3) the eusocial late Homo species with bipedalism, the largest brain, and the unstable habitat; and 4) extended eusocial Homo sapiens with bipedalism, the shrinking brain, omnipresent imagination, and the harsh habitat.

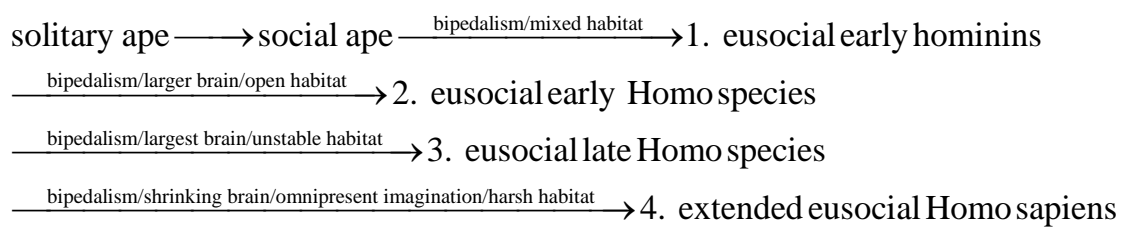

For extended eusocial Homo sapiens, $s \geq 4$ specialists in the division of labor in Equation (3).

\section{Summary}

The paper posits that kin sociality and eusociality are derived from the handicap-care principles based on the need-based care to the handicappers from the caregivers for the self-interest of the caregivers. In this paper, handicap is defined as the difficulty to survive and reproduce independently. Kin sociality is derived from the childhood handicap-care principle where the children are the handicapped children who receive the care from the kin caregivers in the inclusive kin group to survive. The caregiver gives care for the self-interest to reproduce its gene. The individual's gene of kin sociality contains the handicapped childhood and the caregiving adulthood. In the proposed kin sociality investment formula derived from the Hamilton's Rule, the return of the investment (cost) of the caregivers is the surviving genetically related children.

Eusociality is derived from the adulthood handicap-care principle where responsible adults are the handicapped adults who give care and receive care at the same time in the interdependent eusocial group to survive and reproduce its gene. Queen bees reproduce. But must receive care from worker bees that work but must rely on queen bees to reproduce. A caregiver gives care for the self-interest to survive and reproduce its gene. The individual's gene of eusociality contains the handicapped childhood-adulthood and the caregiving adulthood. The handicapped caregivers become the interdependent specialists focusing in one task without doing other tasks for the division of labor. The proposed eusociality investment formula is the kin sociality investment formula modified by the number of the interdependent specialists to enhance the return on investment. For eusocial bees, the number of the interdependent specialists is 3, consisting of infertile female worker bees, and fertile female queen, and fertile male drone. For the eusocial early human ancestors, the number of the interdependent specialists is 3, consisting of fertile homemaker-gatherer, infertile homemaker-gatherer, and fertile explorerhunter. The chronological sequence of the sociality evolution is individual sociality without handicap, kin sociality with handicapped childhood, and eusociality with handicapped adulthood.

In the mixed habitat for the eusocial early hominins, the bipedalism . which initially produced the movement handicap (awkward walking) on the ground and two free hands to large quantities of foods home resulted in the division of labor consisting of homemaker-forager in the safe home area and explorer-forager in the unsafe exploration area. In the open habitat, the eusocial early hominins evolved into the eusocial early Homo species with stone tools, controlled fire, and the large brain. In the unstable habitat, the eusocial early Homo species 
evolved into the eusocial late Homo species with the largest brain. In the harsh habitat during the Upper Paleolithic Period, the eusocial late Homo species evolved into the extended eusocial Homo sapiens with the shrinking brain and omnipresent imagination. The chronological sequence of the eusocial human evolution is 1) the eusocial early hominins with bipedalism and the mixed habitat; 2) the eusocial early Homo species with bipedalism, the larger brain, and the open habitat; 3) the eusocial late Homo species with bipedalism, the largest brain, and the unstable habitat; and 4) extended eusocial Homo sapiens with bipedalism, the shrinking brain, omnipresent imagination, and the harsh habitat.

\section{References}

[1] Crespi, B.J. and Douglas, Y. (1995) The Definition of Eusociality. Behavior Ecology, 6, 109-115. http://dx.doi.org/10.1093/beheco/6.1.109

[2] Wilson, E.O. (2012) The Social Conquest of the Earth. W. W. Norton \& Company. New York.

[3] Hamilton, W. (1964) The Genetical Evolution of Social Behavior I. Journal of Theoretical Biology, 7, 1-16. http://dx.doi.org/10.1016/0022-5193(64)90038-4

[4] Hamilton, W. (1964) The genetical Evolution of Social Behavior II. Journal of Theoretical Biology, 7, 17-52. http://dx.doi.org/10.1016/0022-5193(64)90039-6

[5] Nowak, M.A., Tarnita, C.E. and Wilson, E.O. (2010) The Evolution of Eusociality. Nature, 466, 1057-1062. http://dx.doi.org/10.1038/nature09205

[6] Wilson, D.S. and Wilson, E.O. (2007) Rethinking the Theoretical Foundation of Sociobiology. The Quarterly Review of Biology, 82, 327-348. http://dx.doi.org/10.1086/522809

[7] Roberts, G. (2005) Cooperation through Interdependence. Animal Behaviour, 70, 901-908. http://dx.doi.org/10.1016/j.anbehav.2005.02.006

[8] Aktipis, A. (2015) Principles of Cooperation across Systems: From Human Sharing to Multicellularity and Cancer. Evolutionary Applications, 9, 17-36.

[9] Kapheim, K., et al. (2015) Genomic Signatures of Evolutionary Transitions from Solitary to Group Living. Science, 5, 1139-1143. http://dx.doi.org/10.1126/science.aaa4788

[10] White, T.D., et al. (2009) Ardipithecus Ramidus and the Paleobiology of Early Hominins. Science, 326, 75-86

[11] Carvalho, S., et al. (2012) Chimpanzee Carrying Behaviour and the Origins of Human Bipedality. Current Biology, 22, R180-R181. http://dx.doi.org/10.1016/j.cub.2012.01.052

[12] Lovejoy, C. (2009) Reexamining Human Origins in Light of Ardipithecus Ramidus. Science, 326, 74.

[13] Gardner, R., Garner, B. and Van Cantfort, T. (1989) Teaching Sign Language to Chimpanzees. State University of New York Press, New York.

[14] Corballis, M. (1999) The Gestural Origins of Language. American Scientist, 87, 138-145. http://dx.doi.org/10.1511/1999.2.138

[15] Hickok, G., Bellugi, U. and Klima, E.S. (1996) The Neurobiology of Sign Language and Its Implications for the Neural basis of Language. Nature, 381, 699-702. http://dx.doi.org/10.1038/381699a0

[16] Gibbons, A. (2009) A New Kind of Ancestor: Ardipithecus Unveiled. Science, 326, 36-40.

[17] DiMaggio, E., et al. (2015) Paleoanthropology. Late Pliocene Fossiliferous Sedimentary Record and the Environmental Context of Early Homo from Afar, Ethiopia. Science, 347, 1355-1359.

[18] Anton, S., Potts, R. and Aiello, L. (2014) Evolution of Early Homo: An Integrated Biological Perspective. Science, 345. 6192. http://dx.doi.org/10.1126/science.1236828

[19] Harmand, S., et al. (2015) 3.3-Million-Year-Old Stone Tools from Lomekwi 3, West Turkana, Kenya. Nature, 521, 310-315.

[20] Organ, C., et al. (2011) Phylogenetic Rate Shifts in Feeding Time during the Evolution of Homo. Proceedings of the National Academy of Sciences, 108, 14555-14559. http://dx.doi.org/10.1073/pnas.1107806108

[21] Henneberg, M. (1988) Decrease of Human Skull Size in the Holocene. Human Biology, 60, 395-405.

[22] Hare, B., Wobber, V. and Wrangham, R. (2012) The Self-Domestication Hypothesis: Evolution of Bonobo Psychology Is Due to Selection against Aggression. Animal Behavior, 83, 573-585. http://dx.doi.org/10.1016/j.anbehav.2011.12.007

[23] Hood, B. (2014) The Domesticated Brain. Penguin Books Ltd., London.

[24] Dixson, A. and Dixson, B. (2011) Venus Figurines of the European Paleolithic: Symbols of Fertility or Attractiveness? 
Journal of Anthropology, 2011, Article ID: 569120. http://dx.doi.org/10.1155/2011/569120

[25] Lewis-Williams, D. (2002) The Mind in the Cave: Consciousness and the Origins of Art. Thames \& Hudson, London.

[26] Cunliffe, B. (2001) The Oxford Illustrated History of Prehistoric Europe. Oxford University Press, Oxford.

[27] Klein, R. (1995) Anatomy, Behavior, and Modern Human Origins. Journal of World Prehistory, 9, 167-198. http://dx.doi.org/10.1007/BF02221838

[28] Higham, T. (2014) The Timing and Spatiotemporal Patterning of Neanderthal Disappearance. Nature, 512, $306-309$. http://dx.doi.org/10.1038/nature13621

[29] Bloch, M. (2008) Why Religion Is Nothing Special but Is Central. Philosophical Transactions of the Royal Society B, 363, 2055-2061.

[30] Rand, A. (1979) Introduction to Objectivist Epistemology. New American Library, New York.

[31] Scott, F. and Baron-Cohen, S. (1996) Imagining Real and Unreal Objects: An Investigation of Imagination in Autism. Journal of Cognitive Neuroscience, 8, 400-411. http://dx.doi.org/10.1162/jocn.1996.8.4.371

[32] Angus, D., de Rosnay, M., Lunenburg, P., Terwogt, M.M. and Begeer, S. (2015) Limitations in Social Anticipation Are Independent of Imaginative and Theory of Mind Abilities in Children with Autism but Not in Typically Developing Children. Autism, 19, 604-612. http://dx.doi.org/10.1177/1362361314537911

[33] Henshilwood, C. and Marean, C. (2003) The Origin of Modern Human Behavior: Critique of the Models and Their Test Implications. Current Anthropology, 44, 627-651. http://dx.doi.org/10.1086/377665 